Chronic Obstructive Pulmonary Diseases: Journal of the COPD Foundation

National COPD Readmissions Summit

\title{
The 2nd National COPD Readmissions Summit and Beyond: From Theory to Implementation
}

Kristen S. Willard, MS ${ }^{1}$ Jamie B. Sullivan, $\mathrm{MPH}^{1}$ Byron M. Thomashow, $\mathrm{MD}^{2}$

Catherine S. Jones, PhD, APRN, ANP- ${ }^{3}$ Leonard Fromer, MD ${ }^{4}$ Barbara P. Yawn, MD, MSc 5

Alpesh Amin, MD, MBA, MACP ${ }^{6}$ Jean M. Rommes, $\mathrm{PhD}^{7}$ Rhonda Rotert, MPAS, PA- $\mathrm{C}^{8}$

\begin{abstract}
Chronic obstructive pulmonary disease (COPD) hospitalizations and readmissions adversely impact the health and quality of life of COPD patients. Under the Hospital Readmissions Reduction Program, the Centers for Medicare \& Medicaid Services reduce payments to those hospitals exceeding expected rates of COPD readmissions within 30 days of hospital discharge. It was within this climate that the COPD Foundation held its $2^{\text {nd }}$ COPD Readmissions Summit in March 2015. Experts in attendance: (1) categorized challenges to optimal COPD care, (2) analyzed the state of care delivery and readmissions reduction strategies and (3) identified the best available evidence-based approaches to improving care delivery across the continuum, including early diagnosis via spirometry, ongoing device, oxygen and medication reconciliation, treatment that addresses comorbidities and preventive care, robust patient education, prompt post-acute follow up, home health services and pulmonary rehabilitation. Results of this collaborative event formed the basis for PRAXIS, the COPD Foundation's initiative to improve COPD care across the health continuum and to reduce readmissions.
\end{abstract}

Abbreviations: chronic obstructive pulmonary disease, COPD; emergency department, ED; acute exacerbations of COPD, AECOPD; Centers for Medicare \& Medicaid Services, CMS; Hospital Readmissions Reduction Program, HRRP; National Institutes of Health, NIH; National Heart, Lung and Blood Institute, NHLBI

Funding Support: The $2^{\text {nd }}$ COPD Readmissions Summit and its webcast were sponsored by Sunovion.

Date of Acceptance: August 9, 2016

Citation: Willard KS, Sullivan JB, Thomashow BM, et al. The $2^{\text {nd }}$ National COPD Readmissions Summit and beyond: from theory to implementation. Chronic Obstr Pulm Dis (Miami). 2016;3(4):778-790. doi: http://dx.doi.org/10.15326/jcopdf.3.4.2016.0162

1 COPD Foundation, Washington, D.C.

2 Division of Pulmonary, Allergy and Critical Care Medicine, Department of Medicine, Columbia University Medical Center, New York, New York

3 American Association of Nurse Practitioners and Texas Woman's University, Dallas

4 University of California-Los Angeles, School of Medicine, Los Angeles

5 Department of Family and Community Health, University of Minnesota, Blaine

6 Department of Medicine, University of California, Irvine
7 Emphysema Foundation for Our Rights to Survive (EFFORTS), Kansas City, Missouri

8 McFarland Clinic, Ames, Iowa

Address correspondence to:

Kristen S. Willard

Email: kwillard@COPDFoundation.org

Phone: 866-731-2673 ext. 234

\section{Keywords:}

best practices; care coordination; care transitions; COPD; exacerbations; hospitalizations; HRRP; pulmonary rehabilitation; readmissions 


\section{Introduction}

COPD-related exacerbations cause approximately 700,000 annual hospitalizations and 1.5 million emergency department (ED) visits. ${ }^{1}$ Another 3.8 million hospital stays include COPD as a secondary or complicating condition, illustrating the significant comorbidities associated with this illness. ${ }^{2}$ These hospitalizations and readmissions adversely impact the health and quality of life of COPD patients. Frequent hospitalizations lead to greater impairment in daily living, ${ }^{3-5}$ decreased ability to remain in the workplace ${ }^{4,5}$ and an increased burden on family caregivers. ${ }^{6-8}$ Evidence suggests that frequent exacerbators experience worsening lung function ${ }^{9-11}$ along with faster rates of lung function decline; ${ }^{10,11}$ these individuals are also more likely to have longer hospital stays. ${ }^{11}$ Readmissions within 30 days of discharge and repeated acute exacerbations of COPD (AECOPD) have both been shown to increase mortality risk in patients with COPD. ${ }^{10,12,13}$

In October 2012, the Centers for Medicare \& Medicaid Services (CMS), as part of the Affordable Care Act, were mandated under the Hospital Readmissions Reduction Program (HRRP) to reduce payments made to those hospitals exceeding expected rates of readmission within 30 days of hospital discharge. Reduction of payment takes the form of institutional penalties for exceeding risk-adjusted rates of avoidable readmissions for any cause, even those seemingly unrelated to the initial precipitating admission. Acute myocardial infarction, heart failure and pneumonia were the first readmissions conditions for which penalties were implemented in 2013. In that year, 64\% of hospitals were penalized for excessive readmissions ${ }^{14}$; a disproportionate number of those institutions serve lowincome patients. ${ }^{15}$ In October 2014, CMS expanded their criteria to include index hospitalizations both for hip and knee arthroplasty as well as COPD.

In 2014, it was within this health and policy landscape that the COPD Foundation convened an expert panel of advisory board members - professionals from health care provider backgrounds central to the care of the COPD patient, including pulmonologists, hospitalists, primary care physicians, respiratory therapists, physician assistants, nurses and case managers as well as a COPD patient advocate - to guide the development of a 2nd COPD Readmissions Summit. The committee crafted the 2-day agenda with a multidisciplinary, evidence-based approach, building upon the lessons learned and recommendations resulting from the 1 st COPD Readmissions Summit held in 2013. ${ }^{16}$

The event was held on March 26-27, 2015 at the COPD Foundation's Washington, D.C. offices. More than 100 participants attended, representing a multidisciplinary, diverse group of stakeholders. The largest single group of attendees was physicians, accounting for $30 \%$ of the Summit's total attendance. Respiratory therapists were the next largest group, followed by industry partners. While a conference primarily intended for COPD professionals, the voices of the COPD patient and patient advocates were central to successful outcomes; $5 \%$ of all attendees identified themselves as individuals with COPD. In addition, policy makers were invited to attend and to speak on both HRRP and the overall environment of health care reform and innovation in which COPD care is currently being delivered.

Participants at the 2nd COPD Readmissions Summit met with 3 primary aims: ${ }^{17}$

1. Categorize challenges to optimal COPD care.

2. Analyze the state of care delivery and readmissions reduction strategies.

3. Identify the best available evidence-based approaches to improving care delivery across the health continuum.

This report is a summary of the Summit's discussions, presentations, conclusions and recommendations along with a synopsis of action steps taken since the Summit and plans for the future.

\section{Challenges to Optimal COPD Care}

The following summary and Figure 1 highlight some of the top challenges to care identified at the Summit. ${ }^{18}$

\section{Transitions}

Care coordination gaps and communication issues are pervasive challenges to optimal outcomes. Failures in communication processes or insufficient communication are not specific to any particular group or interaction, but are prevalent throughout the care continuum and among many stakeholders. Breakdowns in continuity of care are most frequently identified in the transition from hospital to home care or other postacute environments (i.e., inadequate discharge planning and follow-up sometimes leading to rehospitalization or overuse of the ED), but the transition from home to hospital is also a frequently missed opportunity. The lack 


\section{Figure 1. Challenges to Optimal COPD Care}
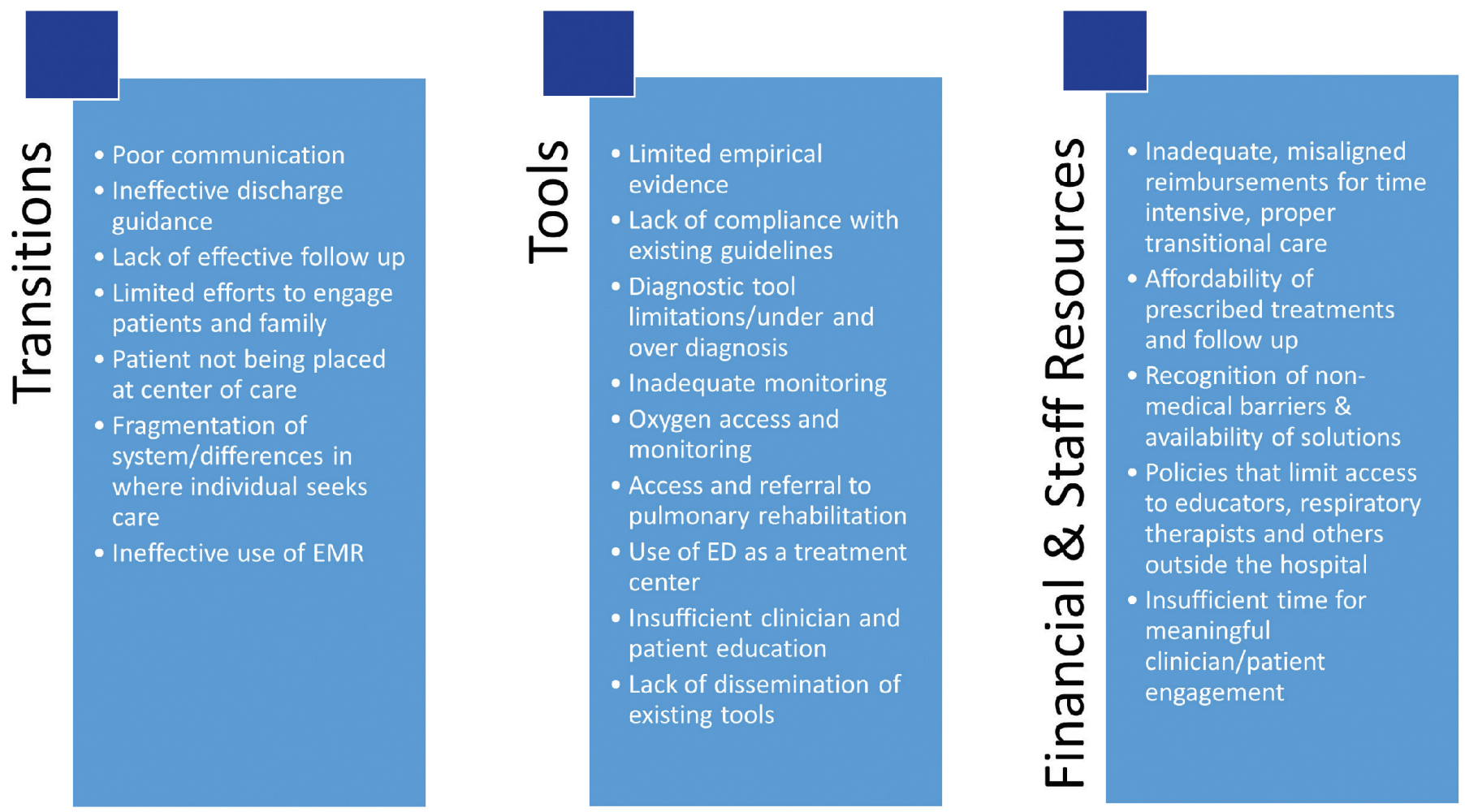

of proactive, team-based approaches to these transitions in care creates a disjointed patient experience.

Incompatible and often insufficient electronic medical record systems can also contribute to the overall problem and are often not consistently used or linked across a health system enterprise; intra-care team and inter-disciplinary communication at times fall short and occasional geographic fragmentation (sometimes within health systems) also impedes access to care.

\section{Tools}

Inadequate diagnostic and other tools and resources serve as additional hurdles to success. Limited patient access to spirometry and issues with competence/a lack of formal training for those administering the test serve as barriers to optimal outcomes. In addition, a lack of evidence-based diagnostic and treatment approaches for COPD as compared to other chronic illnesses can potentially lead to missed or incorrect diagnoses.

Practitioner adherence to available guidelines is a known issue in the COPD care community. A 2011 survey of 500 primary care physicians revealed that only $29.8 \%$ of family medicine and $36.5 \%$ of internal medicine physicians were familiar with the Global initiative for chronic Obstructive Lung Disease (GOLD) guidelines. ${ }^{19,20}$ Research has also shown that actual implementation of these guidelines is also substandard. ${ }^{21}$

Despite a growing enthusiasm toward pulmonary rehabilitation within both the patient and provider communities, referrals to pulmonary rehabilitation are also limited in proportion to COPD's prevalence. ${ }^{2,23}$

\section{Resources}

Insufficient resources are also ubiquitous barriers to success. Financial concerns, related to appropriate services reimbursement (e.g., pulmonary rehabilitation) and coverage for medications, oxygen and followup care, are challenges to best practice. Policies that limit access to respiratory therapists and pharmacists' services outside of the hospital present barriers to better education and engagement, medication reconciliation and disease management. Inadequate staffing models and insufficient time to implement true patientcentered care are other factors hindering success. Last, many of the challenges patients face immediately postdischarge go beyond the disease itself. Health care systems often lack the resources to address these issues, 
including unstable housing, lack of food and a shortage of transportation options.

\section{The Global State of Care Delivery and Readmissions Reduction Strategies}

Summit experts agreed on the following essential care delivery elements. ${ }^{17,18}$

\section{Focus of Care Quality17}

An orientation toward proactive, patient-centered care must be adopted and actively implemented (see Figure 2). ${ }^{17}$ Providers and health systems should embrace processes and employ tools that support them to this end (e.g., risk assessment, an effective approach to predictive modeling and identifying patients vulnerable to readmission, that can support care delivery decisions well before discharge). Adopting a focus solely on readmissions reduction is likely misdirected; if health teams and their organizations commit to a culture of improving care quality for COPD patients, readmissions rates will likely decrease as a natural result.

\section{Figure 2. Models of Care}

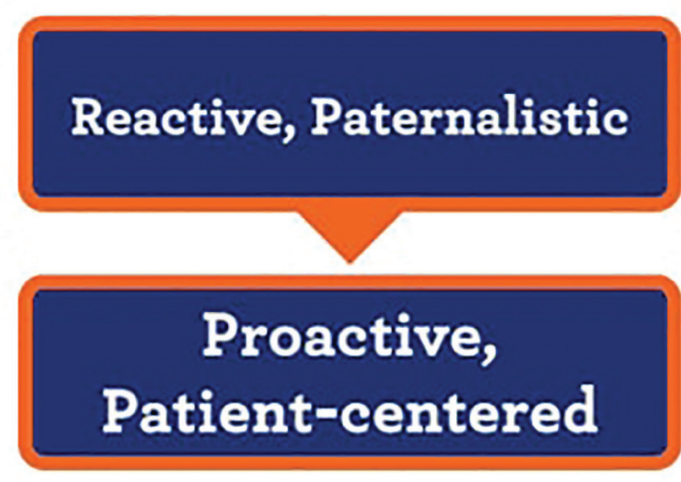

\section{A Multi-Disciplinary Team Approach with 360-Degree Accountability}

Success in treating the COPD patient and preventing unnecessary hospitalizations is not solely about the disease. To succeed, an expectation of 360-degree accountability will need to be accepted by all stakeholders - the patient, family, caregiver and the treatment team - both during and post-hospitalization (Figure 3). ${ }^{17}$ All will need to take increased responsibility for improving communication and ensuring patient needs are met.

In many cases, this may involve a change to either

\section{Figure 3. 360-degree Accountability}

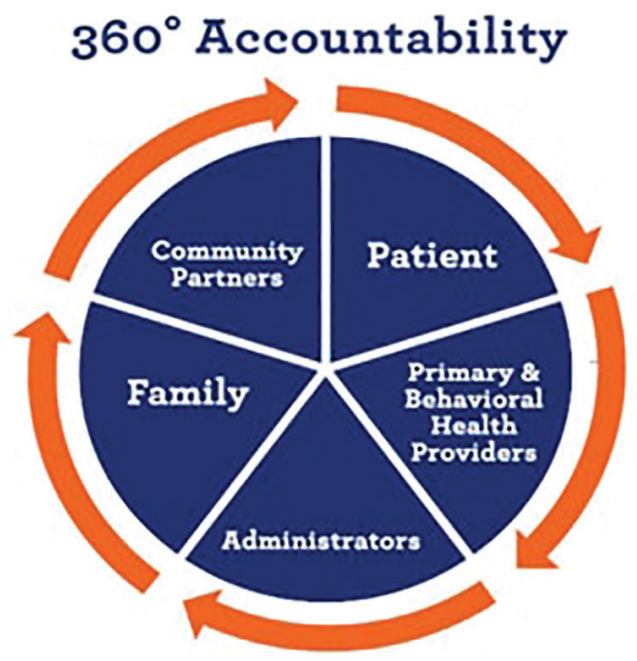

the care team's structure or current processes - or both. Clearly defined roles and responsibilities and the involvement of multidisciplinary team members throughout the patient experience should serve to improve patient outcomes. Other promising practices include: workflow redesign that may include task grid checklists; the establishment of multidisciplinary COPD clinics, at which pulmonologists, respiratory therapists, pharmacists and other central care team members might provide ongoing care to those with COPD under one roof; patient-centered teams in which patients and caregivers serve a central role in determining what is best for the individual patient and process-oriented programs.

The central role of a transitional care coordinator or case manager anchoring a multi-disciplinary care team may also improve outcomes. The introduction of a care coordinator allows for ongoing appreciation of a patient's entire clinical picture while specialists focus on more discrete areas of patient care and helps to ensure smoother care transitions. Given the predominance of patients with COPD in EDs, transitional care coordinators can likely play a more active and beneficial role within this environment than they are currently. In the absence of a care coordinator, leads or champions identified within multi-disciplinary teams can also be assets to patient care.

Respiratory therapists should be included as central members of the health care team for people with 
COPD while hospitalized and post-discharge. For those organizations that have not yet included respiratory therapists in their COPD care teams as well as those who have integrated them into their care processes, efforts should be made to clearly elucidate the role of respiratory therapy and therapists at every stage of care.

\section{Improved Care at Transitions Points}

Efforts to improve transition management should be made not only between settings (e.g., hospital to home) but between care providers. Improvements can be as simple as ensuring other team members' chart notes are read thoroughly, or more complex, including effecting cultural change that emphasizes the importance of: (1) transition points beyond discharge and (2) the involvement of all team members at these crucial points. Discharge coordinators, who can direct discharge logistics and communication, can also help to improve the transition from hospital to home or other setting. In those situations where a patient transitions from the ED back to the community, the ED team also plays a vital and time-limited role in the lives of their COPD patients. Clear, succinct and consistent communications are especially needed in this demanding acute care environment.

\section{Continued Innovation is Needed17}

In those areas in which the status quo is not proving effective, innovative technology and approaches are now needed. While there is often a focus on purely technological innovation as one of the available means to improving patient care (e.g., telemedicine and virtual patient education, biosensors and wearables), continued "outside-the-box thinking" can produce innovative process solutions to standing problems (e.g., care process redesign, design thinking). Innovation also demands evaluation; effectiveness research needs to keep pace with these promising innovations (and the COPD care community's current best practices).

\section{Identify the Best Available Evidence- Based Approaches to Improving Care Delivery Across the Health Continuum ${ }^{17}$}

\section{Best Practices}

COPD patients only receive evidence-based care about half of the time. ${ }^{24}$ While no panacea exists, providers must implement those practices with demonstrated benefits and adhere to established diagnostic and treatment guidelines. There is a particular need for:

\section{Accurate and Early Diagnosis Using Spirometry}

The GOLD guidelines state that "spirometry is now required to make a confident diagnosis of COPD."20 However, spirometry is consistently underused internationally in both primary care and pulmonary specialty environments. ${ }^{25-28}$ A 2007 U.S. study found that fewer than one-third of participants with a confirmed diagnosis of COPD had been diagnosed via spirometry; in this study, use of diagnostic spirometry also decreased with ascending patient age. ${ }^{29}$ Another survey asked nurse practitioners to identify symptoms of individuals with COPD and to describe the use of spirometry in aiding the diagnosis. The majority of respondents were able to identify three principal symptoms of the disease, but many were not familiar with other common symptoms or mistakenly attributed these symptoms to other disease processes. Although standard guidelines state that post-bronchodilator values are to be used in making the diagnosis of COPD, this approach was uncommonly utilized by the nurse practitioners surveyed. ${ }^{30}$

\section{Regular and Consistent Oxygen, Device and Medication Reconciliation}

On average, each hospitalized patient is susceptible to one or more medication errors daily. ${ }^{31}$ This can be of particular concern in those with COPD given the number and complexity of comorbidities with which they present. The presence of a systematic medication reconciliation process should serve to minimize error and maximize patient outcomes.

Given that oxygen is one of 4 interventions shown to decrease mortality in patients with AECOPD, ${ }^{32}$ management should also extend to oxygen, as well as all medical devices (including noninvasive ventilation devices often used for comorbid sleep apnea). This process needs to be implemented at every site of care (e.g., hospital, ED, home). For example, even if a patient requires oxygen during a hospitalization and at discharge, once stabilized, oxygen needs may well decrease or disappear; oxygen needs should be rechecked regularly at follow-up visits.

Given the essential nature of oxygen for many COPD patients, both providersand patients mustalso familiarize themselves with the variety of systems available as well as policies impacting oxygen availability and access. Results from the Long Term Oxygen Treatment Trial will be published in 2016 and other studies are underway to 
identify effective mechanisms for improving adherence to oxygen therapy and to identify the barriers currently faced by patients such as unavailable suppliers, lack of education provided by suppliers and lack of follow-up to ensure the patient is matched with the best delivery system for their lifestyle and clinical needs.

\section{Treatment That Addresses Comorbidities and Preventive Care}

A 2006 COPD Foundation study found that in a household sample of COPD patients, $81 \%$ reported having 6 or more comorbid conditions. ${ }^{33}$ Therefore, it is crucial that an accurate and comprehensive evaluation for all behavioral and primary health comorbidities be completed while the patient is hospitalized. In addition, it is imperative that a home evaluation be conducted to evaluate psychosocial determinants of health (e.g., what food, transportation, financial and social support are available to the person with COPD in the postacute environment?) Preventive care should include education on smoking cessation, avoiding second-hand smoke and other pollutants and both influenza and pneumococcal immunizations.

\section{Employing Effective Patient Education Strategies}

Without appropriate COPD patient engagement and education, adherence to medication and device instructions is compromised; non-adherence rates to COPD medications may be as high as 57\%. ${ }^{34}$ Areas for improvement include appreciating a patient and caregiver's level of health literacy; understanding their confusion; if possible and appropriate, limiting the number of devices used in a patient's care; and introducing professional education across all disciplines involved in family and patient engagement. Evidencebased educational methods such as motivational interviewing and communication must be employed; the teach-back technique is one strategy that has increased correct inhaler use in COPD patients. ${ }^{35}$

\section{Post-Acute Follow Up No Later Than 7 Days Post- Discharge}

A follow-up office visit within 7 days has been shown impactful in reducing readmissions in those with multiple chronic conditions. ${ }^{36}$ In a sample of more than 62,000 COPD patients, follow-up with a primary care physician within 30 days was shown to be associated with significantly reduced risk for readmission and ED visit. $^{37}$

\section{Home-Based Health Care and Community Services, When Appropriate}

Approximately two-thirds of COPD patients are discharged to the home environment. ${ }^{38}$ There is evidence for home health and community-based interventions being beneficial for those with more severe $\mathrm{COPD}^{39,40}$ as well as for home-based pulmonary rehabilitation's association with some improved outcomes, including exercise capacity and quality of life. ${ }^{41-43}$ Telehealth is another expanding area in which outcomes are now being studied with greater frequency; while a 2012 review cited low quality and conflicting evidence in this arena, more recent studies have shown significant reductions in hospitalization rates for those with COPD. ${ }^{44,45}$

Homecare agencies that serve the COPD population market have adapted and now tailor their programs, some in shared risk models, to reducing readmissions. CMS' Partnership for Patients program is one of many seeking to develop evidence in this area through demonstration projects like the Community-Based Care Transitions Program which funds 27 efforts to develop and disseminate best practices. ${ }^{46}$

\section{Recognizing Pulmonary Rehabilitation as a National Imperative, to be Made Available to Appropriate Patients and Reimbursed Accordingly}

The American Thoracic Society and several other prominent professional organizations have reviewed the evidence for the effectiveness of pulmonary rehabilitation, and have indicated that these programs have demonstrated impact in reducing impairment and future risk: reducing dyspnea; increasing exercise ability; and improving health status, including emotional function. ${ }^{47}$ A comprehensive 2015 Cochrane review supports these findings. ${ }^{48}$ While crucial, the patientreported benefits of pulmonary rehabilitation extend well beyond the physical. Pulmonary rehabilitation programs support patient well-being and selfmanagement, given that much of a patient's general health, nutrition and disease-specific education may be received through classes. Social support is also derived in an environment that promotes peer interaction. ${ }^{47}$

Despite the known benefits, access to pulmonary rehabilitation remains limited. Where it is available, referrals and uptake among patients is low. ${ }^{49}$ A 2010 National Coverage Determination for Medicare patients resulted in standard coverage for 36-72 lifetime 
sessions; however, reimbursement rates plummeted, existing facilities struggled to stay solvent and huge areas of the country now have little to no access. Policy change is needed. In addition to increased reimbursement and increased awareness of the benefits of pulmonary rehabilitation, the policy community must address the burdensome need for a supervising physician to be immediately available at a pulmonary rehabilitation site. ${ }^{50}$

\section{Continuing to Expand Our Knowledge Base}

Gaps in knowledge exist across the entire COPD care continuum. In early 2016, the National Institutes of Health's (NIH's) National Heart, Lung and Blood Institute (NHLBI) convened dozens of stakeholders to develop a National COPD Action Plan and recognized this limitation. One of NHLBI's 6 goals was to "increase and sustain research to better understand prevention, pathogenesis, diagnosis, treatment, and management of COPD." Continued basic and translational research must be conducted to reach the COPD community's ambitious goals.

In addition, while readmissions rates are used to gauge success, their clinical significance is unknown. The average COPD readmissions rate is $20.7 \%{ }^{51}$ Medicare data from July 2010 to June 2013 show a $12 \%$ decrease in the COPD readmissions for adults 65 and older. ${ }^{52}$ It is still unclear, however, precisely what factors are responsible for this decline and whether reducing rehospitalizations clearly means that patient care, quality of life and clinical outcomes have improved. Additional research is warranted to clarify these associations.

\section{Since the Summit}

Immediately following the 2015 2nd COPD Readmissions Summit, the COPD Foundation's care delivery staff began working to further research the challenges and proposed remedies for current limitations in optimal COPD care. The COPD Foundation:

1. Developed and launched PRAXIS, the Foundation's initiative for professionals, based online at www.COPDFoundation.org/PRAXIS. In April 2015, staff began an extensive review of the existing care delivery and readmissions reduction literature and transcribed the essential elements from the 2015 Readmissions Summit replay. Out of this distillation, 29 topics emerged as high-level groupings in which all presentations, statistics, toolkits, research articles, case studies and Summit discussion content could be categorized. This list includes: behavioral health, care coordination, comorbidities, hospitalizations, patient engagement, patient experience, pulmonary rehabilitation, quality improvement, post-acute care and readmissions (a full list of topics can be found in Table 1).

2. This ongoing analysis produced the PRAXIS Resource Repository (https://www.copdfoundation. org/Praxis/Resource-Repository/Search.aspx) an evidence-based best practices and quality improvement hub devoted to COPD care delivery. Inclusion in this library required that content meet several conditions:

-It was of a topic relevant to COPD care delivery and was appropriate for an audience of health care providers, administrators or policy makers.

- If a research paper, it: was published in an established, peer-reviewed journal and reflected the most rigorous methodology available for that topic.

-The resource included demonstrated outcomes. Efforts were made to ensure both findings of statistical and clinical significance were reflected, when possible.

As of July 2016, the PRAXIS resource repository holds more than 180 toolkits, presentations, statistics, research papers, articles and other support materials and is continuing to grow as the literature and best practice space expands.

3. The Foundation also created and enhanced the PRAXIS Nexus (https://www.copdfoundation.org/ Praxis/Community/Blog.aspx), a blog of original COPD care delivery articles. Content includes outcomes-based best practice interviews, relevant $\mathrm{CMS}$ and other policy analyses, resource highlights (e.g., COPD action plans, International Classification of Diseases, 10th Revision coding sheets, root cause analysis materials), patient experience features and care delivery support articles (e.g., assessing adherence to medication regimens, implementing shared decision making approaches). The blog contains more than 60 original articles.

4. The PRAXIS site also contains an interactive social community, where health care providers, administrators and policy makers can share 


\section{Table 1. PRAXIS Resource Repository Categories}

\begin{tabular}{|c|c|c|c|c|}
\hline Alpha-1 & Diagnosis & HRRP & $\begin{array}{l}\text { Post-acute } \\
\text { care }\end{array}$ & Readmission \\
\hline $\begin{array}{l}\text { Ambulatory } \\
\text { care }\end{array}$ & $\begin{array}{l}\text { Evaluation \& } \\
\text { quality } \\
\text { improvement }\end{array}$ & Nutrition & Prevention & $\begin{array}{l}\text { Risk } \\
\text { stratification }\end{array}$ \\
\hline $\begin{array}{l}\text { Behavioral } \\
\text { health }\end{array}$ & Exacerbations & Oxygen & $\begin{array}{l}\text { Promising } \\
\text { practices }\end{array}$ & $\begin{array}{l}\text { Socioeconomic } \\
\text { issues }\end{array}$ \\
\hline $\begin{array}{l}\text { Care } \\
\text { coordination }\end{array}$ & Exercise & $\begin{array}{l}\text { Palliative } \\
\text { care }\end{array}$ & Public policy & Telehealth \\
\hline $\begin{array}{l}\text { Caregiver \& } \\
\text { community }\end{array}$ & Hospice & $\begin{array}{l}\text { Patient } \\
\text { education }\end{array}$ & $\begin{array}{l}\text { Pulmonary } \\
\text { rehabilitation }\end{array}$ & Treatment \\
\hline Comorbidities & Hospitalization & $\begin{array}{l}\text { Patient } \\
\text { experience }\end{array}$ & $\begin{array}{l}\text { Quality } \\
\text { improvement }\end{array}$ & \\
\hline
\end{tabular}

breaking news as well as provider-specific care delivery questions; as well as centers devoted to public policy and advocacy, professional development and innovation. More than 9300 health care providers now belong to PRAXIS and more than 10,000 recipients are sent bi-weekly e-newsletters containing the most up-to-date and relevant postings.

5. To support the use of and further promote understanding of these materials, the PRAXIS team conducted more than 20 webinars orienting professionals to (1) the background for the PRAXIS initiative, (2) the development of its distinct sections and their intended use and (3) successful navigation of the website and its best practices.

6. In 2016, the COPD Foundation's PRAXIS staff began outreach to hospitals and health systems to translate these resources into personalized implementation guidance. Outreach is conducted through targeted correspondence to new professionals joining the PRAXIS community, calls to hospitals and health systems facing substantial readmissions penalties and event networking. The care delivery team offers individualized consultation to those interested in improving their care delivery approaches.

For example, staff recently connected with a medical center-based COPD educator filling a newly created position. The Foundation team discussed the center's current COPD care delivery process as well as approaches for both improvement and expansion of their work. In these types of outreach meetings, staff encourage the use of approaches for more immediate implementation (e.g., adopting COPD action plans at all points of care, identifying effective patient and family education materials, adding resources to discharge instructions) and long-term quality improvement strategies (e.g., expansion into a multidisciplinary team that includes not only the aforementioned acute care providers but also health system administrators and community professionals and engagement with community partners such as skilled nursing facilities). These meetings are in their initial stages and focus on the earliest phases of program improvement and evaluation: planning and implementation. Continued efforts, including those discussed below, will incorporate both formative and summative evaluation into each organization's efforts.

Figure 4 is an example of the evidence-based elements identified at the Summit and the stages of care at which each can be incorporated. Health systems are encouraged to employ the appropriate tools, processes and interventions across the continuum - well before discharge - and to use those that are best matched to their patients' needs and resource availability.

\section{Conclusions and Next Steps}

While the creation of PRAXIS has filled a substantial educational and support infrastructure need in the COPD professional community, considerable work remains. The community does not yet have the appropriate home care or pulmonary rehabilitation reimbursement structure necessary to sustain these programs for the long term. Researchers have not yet identified a cure-all for intra-team communications issues, determined the precise combination of patient education and intensive follow up leading to optimal patient outcomes, or discovered the ideal process for ensuring spirometry is used to diagnose the greatest number of patients at the earliest stage of their disease. While overall readmissions rates are decreasing, ${ }^{52}$ researchers and administrators cannot directly account for the factors related to their decline, nor describe their impact on the COPD patient and his or her family. The work must continue.

The next phase of the COPD Foundation's care delivery improvement initiatives will mark a natural transition from theory discussion and best practice 


\section{Figure 4. Evidence-based Interventions Across the Health Continuum}
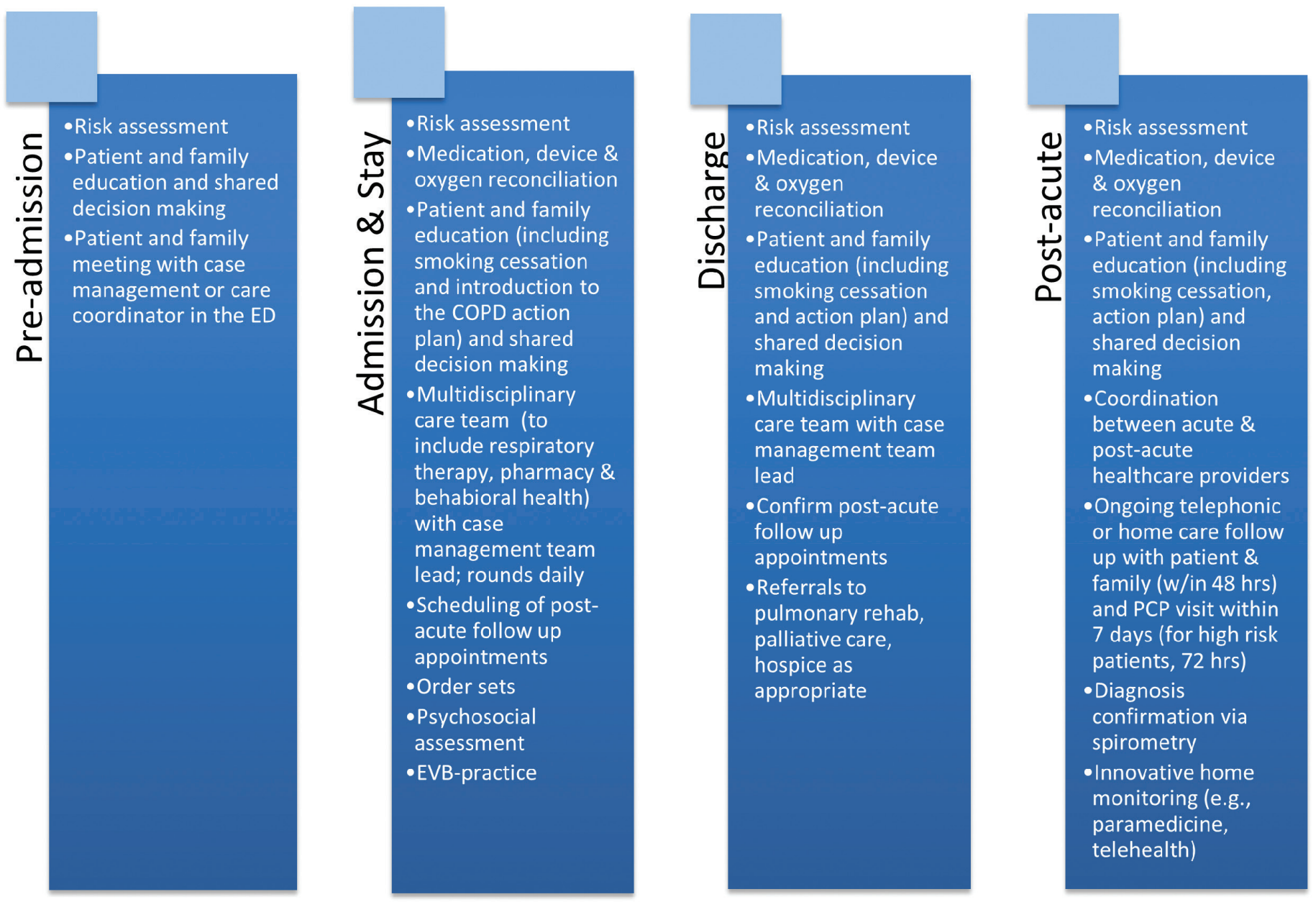

identification to implementation and translational research and evaluation. Drawing upon (1) the priorities identified at the 2015 Readmissions Summit, (2) evidence-based practices culled in populating the PRAXIS Resource Repository and blog, (3) experiences of COPD Foundation experts and the health systems supported as part of PRAXIS outreach and (4) the individual needs and goals of participating organizations, the COPD Foundation will now host a 2017 COPD Readmissions Reduction Institute.

The goal of the event will be to discuss and disseminate care delivery and readmissions reduction best practices to a select group of multidisciplinary attendees. The focus of this state-level event will be the translation of research to concrete implementation for these varied stakeholders; the approach will be a hands-on, collaborative one that encourages both

event and ongoing participation via brainstorming, targeted process improvement conversations with the Foundation's care delivery team and community engagement via the PRAXIS website.

In this next phase of care delivery support, the Foundation will also transition from a focus on outputs to outcomes. For example, before leaving the event, attendees will be required to develop implementation goals for use upon their return to their home organizations. Limited attendance at the event will allow COPD Foundation staff to conduct high-touch follow up with each of the attending groups to support their efforts and check progress against their plans. Ongoing participant reporting will allow for the documentation of progress as well as challenges encountered and lessons learned. Outcomes from the event will include attendee implementation of organization-appropriate 
best practices and, ultimately, an analysis of attendee readmissions rates in relation to best practice implementation.

The COPD Foundation is one of many organizations focused on identifying solutions to critical care delivery questions facing the COPD community. Since the first COPD Readmissions Summit in October 2013, it has been clear that the inclusion of penalties for AECOPD has had one outcome: increased attention to the need to improve care for COPD patients. The first Summit uncovered the lack of evidence to support programs attempting to reduce readmissions after AECOPD and the lack of inclusion of COPD within broad models and demonstrations underway in other common conditions. Nearly 18 months later, the 2nd COPD Readmissions Summit showcased that not only has interest grown in the issue, the knowledge base that is grounded in evidence is growing and the programs that include COPD as a focus are proliferating with or without a grounding in peer-reviewed evidence.

The need to act is urgent and the process of building evidence is too slow to keep pace. As the second Readmissions Summit and the subsequent work within PRAXIS has shown, the COPD care community can implement our most promising practices as the intense pursuit of innovation and further evidencebased solutions continues. We can and must do both to achieve our best outcomes for all patients with COPD.

\section{Acknowledgements}

The authors thank these additional 2nd Readmissions Summit Advisory Board members and speakers as well as the PRAXIS Advisory Board: Becky Anderson, RRT, Janice Cotton, Kimberly Driscoll, PhD, Kathleen Fraser, RN-BC, MSN, MHA, CRRN, Danny Fu, PharmD, CDE, Thomas J. Kallstrom, MBA, RRT, FAARC, deNay Porter Kirkpatrick, DNP, APN-BC, Jerry Krishnan, MD, PhD, Paul McGann, MD, Deb McGowan, RN, BSN, ACM, CHCP, Valerie G. Press, MD, MPH, Tina Shah, MD, MPH, Gulshan Sharma, MD, Robert Silverman, MD, MS, John W. Walsh, J. Andrew (Andy) Woods, PharmD, BCPS and Jean Wright, MD, MBA.

\section{Declaration of Interest}

KSW and JLS are employed by the COPD Foundation and received grant funding from Sunovion for this work. BMT reports personal fees from Boehringer-Ingelheim, Astra Zeneca, GlaxoSmithKline and Novartis outside the submitted work. LF reports personal fees from Boehringer-Ingelheim outside the submitted work. BPY reports grants and other from Boehringer-Ingelheim and other from Astra Zeneca, TEVA Pharmaceutical and GlaxoSmithKline outside the submitted work. JMR reports personal fees from Nonin, the Carolinas Health System and the RELIANCE study. She is also a member of the COPD Patient Powered Research Network Governing Board. 


\section{References}

1. Ford E, Croft J, Mannino D, Wheaton A, Zhang X, Giles W. COPD Surveillance-United States, 1999-2011. Chest. 2013; 144(1): 284-305.

doi: http://dx.doi.org/10.1378/chest.13-0809

2. Wier L, Elixhauser A, Pfuntner A, Au D. Overview of Hospitalizations among Patients with COPD, 2008 In: Healthcare Cost and Utilization Project (HCUP) Statistical Briefs. Rockville, MD: Agency for Healthcare Research and Quality (US); 2011. http://www.ncbi.nlm.nih.gov/books/NBK53969/. Accessed July 20, 2016.

3. Bendixen H, Ejlersen Wæhrens E, Wilcke J, Sørensen L. Selfreported quality of ADL task performance among patients with COPD exacerbations. Scand J Occup Ther. 2014; 21(4):313-320. doi: http://dx.doi.org/10.3109/11038128.2014.89962

4. Rennard S, Decramer M, Calverley P, et al. Impact of COPD in North America and Europe in 2000: subjects' perspective of Confronting COPD International Survey. Eur Respir J. 2002; 20(4):799-805.

doi: http://dx.doi.org/10.1183/09031936.02.03242002

5. Wheaton AC, Cunningham TJ, Ford ES, Croft JB. Employment and activity limitations among adults with chronic obstructive pulmonary disease - United States, 2013. MMWR Morb Mortal Wkly Rep. 2016; 64(11):289-295. http://www.cdc.gov/mmwr/ preview/mmwrhtml/mm6411a1.htm. Accessed July 20, 2016.

6. Burton A, Sautter J, Tulsky J, et al. Burden and well-being among a diverse sample of cancer, congestive heart failure, and chronic obstructive pulmonary disease caregivers. J Pain Symptom Manage. 2012; 44(3):410-420.

doi: http://dx.doi.org/10.1016/j.jpainsymman.2011.09.018

7. Pinto RA, Holanda MA, Medeiros MM, et al. Assessment of the burden of caregiving for patients with chronic obstructive pulmonary disease. Respir Med. 2007;101:2402-2408.

doi: http://dx.doi.org/10.1016/j.rmed.2007.06.001

8. Han M, Martinez C, Au D et al. Meeting the challenge of COPD care delivery in the USA: a multiprovider perspective. Lancet Res Med. 2016;4(6):473-526.

doi: http://dx.doi.org/10.1016/s2213-2600(16)00094-1.

9. Hurst JR, Vestbo J, Anzueto A, et al. Susceptibility to exacerbation in chronic obstructive pulmonary disease. $N$ Engl J Med. 2010; 363:1128-1138.

doi: http://dx.doi.org/10.1056/NEJMOA0909883

10. Halpin DM, Decramer M, Celli B, Kesten S, Liu D, Tashkin DP. Exacerbation frequency and course of COPD. Int J Chron Obstruct Pulmon Dis. 2012;7:653-661.

doi: http://dx.doi.org/10.2147/COPD.S34186

11. Donaldson G, Seemungal TA, Bhowmik A, Weezicha JA. Relationship between exacerbation frequency and lung function decline in chronic obstructive pulmonary disease. Thorax. 2002; 57(10): 847-852. doi: http://dx.doi.org/10.1136/thorax.57.10.847.
12. Guerrero M, Crisafulli E, Liapikou A, et al. Readmission for acute exacerbation within 30 days of discharge is associated with a subsequent progressive increase in mortality risk in COPD patients: a long-term observational study. PLoS One. 2016; 11(3): e0150737. doi: http://dx.doi.org/10.1371/journal.pone.0150737

13. Soler-Cataluna J, Martinez-Garcia M, Roman S, Salcedo E, Navarro M, Ochando R. Severe acute exacerbations and mortality in patients with chronic obstructive pulmonary disease. Thorax. 2005; 60(11):925-931.

doi: http://dx.doi.org/10.1136/thx.2005.040527.

14. Boccuti C, Casillas G. Aiming for fewer hospital U-turns: the Medicare hospital readmission reduction program. The Henry J. Kaiser Family Foundation Issue Brief. January 2015. http:// kff.org/medicare/issue-brief/aiming-for-fewer-hospital-uturns-the-medicare-hospital-readmission-reduction-program/. Accessed July 20, 2016.

15. American Hospital Association. Trendwatch: Rethinking the hospital readmissions reduction program. American Medical Association web site. http://www.aha.org/research/reports/ tw/15mar-tw-readmissions.pdf.

Published March 2015. Accessed July 19, 2016.

16. Krishnan JA, Gussin HA, Prieto-Centurion V, Sullivan JL, Zaidi F, Thomashow BM. National COPD Readmissions Summit: Integrating COPD into patient-centered hospital readmissions reduction programs. Chronic Obstr Pulm Dis (Miami). 2015; 2(1): 70-80. doi: http://dx.doi.org/10.15326/JCOPDF.2.1.2014.0148

17. Thomashow B, Sullivan, J, Willard K. Lessons of impact from the COPD Foundation's 2nd Readmissions Summit. Poster presented at: COPD10; June 2016; Birmingham, UK.

18. Group oral discussions and summary presentations at: 2nd COPD Readmissions Summit; March 26-27, 2016; Washington, D.C.

19. Salinas GD, Williamson JC, Kalhan R, et al. Barriers to adherence to chronic obstructive pulmonary disease guidelines by primary care physicians. Int J Chron Obstruct Pulmon Dis. 2011; 6:171179. doi: http://dx.doi.org/10.2147/COPD.S16396.

20. Global initiative for chronic Obstructive Lung Disease (GOLD). Global strategy for diagnosis, management and prevention of COPD. GOLD website. http://goldcopd.org/global-strategydiagnosis-management-prevention-copd-2016/ Published 2001. Updated December 2015. Accessed September 2016.

21. Overington JD, Huang YC, Abramson MJ, et al. Implementing clinical guidelines for chronic obstructive pulmonary disease: barriers and solutions. J Thorac Dis. 2014; 6(11):1586-1596. doi: http://dx.doi.org/10.3978/j.issn.2072-1439.2014.11.25 .

22. Yawn BP, Wollan PC. Knowledge and attitudes of family physicians coming to COPD continuing medical education. Int J Chron Obstruct Pulmon Dis. 2008; 3(2):311-318.

http://www.ncbi.nlm.nih.gov/pmc/articles/PMC2629969/ 
23. Johnston K, Grimmer-Somers K. Pulmonary rehabilitation: overwhelming evidence but lost in translation? Physiother Can. 2010; 62(4):368-373.

doi: http://dx.doi.org/10.3138/physio.62.4.368

24. Mularski R, Asch S, Shrank W, et al. The quality of obstructive lung disease care for adults in the United States as measured by adherence to recommended processes. Chest. 2006; 130(6):18441850. doi: http://dx.doi.org/10.1378/chest.130.6.1844

25. Bourbeau J, Sebaldt RJ, Day A, et al. Practice patterns in the management of chronic obstructive pulmonary disease in primary practice: The CAGE study. Can Respir J. 2008;15(1):1319. http://www.ncbi.nlm.nih.gov/pubmed/18292848

26. Walters JA, Haydn Walters E, Nelson M, et al. Factors associated with misdiagnosis of COPD in primary care. Prim Care Respir J. 2011; 20(4): 396-402.

doi: http://dx.doi.org/10.4104/pcrj.2011.00039

27. Nishi SPE, Wang Y, Kuo Y-F, Goodwin JS, Sharma G. Spirometry use among older adults with chronic obstructive pulmonary disease: 1999-2008. Ann Am Thorac Soc. 2013; 10(6): 565-573. doi: http://dx.doi.org/10.1513/AnnalsATS.201302-037OC .

28. Moore P. Practice management and chronic obstructive pulmonary disease in primary care. Am J Med. 2007; 120(8): S23-S27. doi: http://dx.doi.org/10.1016/j.amjmed.2007.04.009

29. Han MK, Kim MG, Mardon R, et al. Spirometry utilization for COPD: how do we measure up? Chest. 2007; 132: 403-409. doi: http://dx.doi.org/10.1378/chest.06-2846

30. Blair KA, Evelo AJ. COPD: Overview and survey of NP knowledge. Nurse Pract. 2013; 38(6): 18-26. doi: http://dx.doi.org/10.1097/01.NPR.0000429892.18502.79

31. Aspden P, Wolcott JA, Bootman JL, Cronenwett LR, eds. Preventing Medication Errors. Washington, DC: Committee on Identifying Medication Errors, Board on Health Services, Institute of Medicine; 2007. http://www.nap.edu/read/11623/ chapter/1. Accessed July 19, 2016.

32. Croxton TL, Bailey WC. Long-term oxygen treatment in chronic obstructive pulmonary disease: recommendations for future research-an NHLBI workshop report. Am J Respir Crit Care Med. 2006; 174: 373-378.

doi: http://dx.doi.org/10.1164/rccm.200507-1161WS

33. Barr RG, Celli BR, Mannino DM, et al. Comorbidities, patient knowledge and disease management in a national sample of chronic obstructive pulmonary disease. Am J Med. 2009; 122(4):348-355.

doi: http://dx.doi.org/10.1016/j.amjmed.2008.09.042

34. Bryant J, McDonald VM, Boyes A, Sanson-Fisher R, Paul $\mathrm{C}$, Melville J. Improving medication adherence in chronic obstructive pulmonary disease: a systematic review. Respir Res. 2013; 14 (1). doi: http://dx.doi.org/10.1186/1465-9921-14-109
35. Dantic DE. A critical review of the effectiveness of 'teach-back' technique in teaching COPD patients self-management using respiratory inhalers. Health Edu J. 2014; 73(1):41-50. doi: http://dx.doi.org/10.1177/0017896912469575

36. Jackson C, Shahsahebi M, Wedlake T, et al. Timeliness of outpatient follow-up: an evidence-based approach for planning after hospital discharge. Ann Fam Med. 2015; 13:115-22. doi: http://dx.doi.org/10.1370/afm.1753

37. Sharma G, Kuo Y-F, Freeman JL, Zhang DD, Goodwin JS. Outpatientfollow-upvisit and 30-dayemergency departmentvisit and readmission in patients hospitalized for chronic obstructive pulmonary disease. Arch Intern Med. 2010; 170(18):1664-1670. doi: http://dx.doi.org/10.1001/archinternmed.2010.345

38. Han MK, Martinez CH, Au DH, et al. Meeting the challenge of COPD care delivery in the USA: a multiprovider perspective. Lancet Respir Med. 2016; 4(6): 473-526. doi: http://dx.doi.org/10.1016/S2213-2600(16)00094-1

39. Spiliopoulos N, Clark E, Donoghue J, Dunford M. Outcomes from a respiratory coordinated care program (RCCP) providing community-based interventions for COPD patients from 1998 to 2006. Contemp Nurse. 2009; 31(1): 2-8. doi: http://www.ncbi. nlm.nih.gov/pubmed/19117496

40. Pushparajah S, Mcclellan R, Henry A, et al. Use of a chronic disease management programme in COPD to reduce hospital admissions. Chron Respir Dis. 2006; 3:187-193.

41. Grosbois J-M, Gicquello A, Langlois C, et al. Long term evaluation of home-based pulmonary rehabilitation in patients with chronic obstructive pulmonary disease. Int $J$ Chron Obstruct Pulmon Dis. 2015; 25(10): 2037-2044. doi: https://dx.doi.org/10.2147/COPD.S90534

42. do Nascimento ES, Sampaio LM, Peixoto-Souza FS, et al. Homebased pulmonary rehabilitation improves clinical features and systemic inflammation in chronic obstructive pulmonary disease patients. Int J Chron Obstruct Pulmon Dis. 2015; 10: 645-653. doi: https://dx.doi.org/10.2147/COPD.S76216

43. Liu XL, Tan JY, Wang T, et al. Effectiveness of home-based pulmonary rehabilitation for patients with chronic obstructive pulmonary disease: a meta-analysis of randomized controlled trials. Rehabil Nurs. 2014; 39(1): 36-59. doi: http://dx.doi.org/10.1002/rnj.112

44. Holland A. Telehealth reduces hospital readmission rates in patients with COPD. J Physiother. 2013; 59(2): 129. doi: http://dx.doi.org/10.1016/S 1836-9553(13)70168-1

45. Segrelles Calvo G, Gómez-Suárez C, Soriano JB, et al. A home telehealth program for patients with severe COPD: the PROMETE study. Respir Med. 2014; 108: 453-462. doi: http://dx.doi.org/10.1016/j.rmed.2013.12.003 
46. Centers for Medicare and Medicaid Services (CMS). Community-based Care Transitions Program. CMS web site. https://innovation.cms.gov/initiatives/CCTP/ . Updated July 20, 2016. Accessed July 29, 2016.

47. Nici L, Donner C, Wouters E, et al for the ATS/ERS Pulmonary Rehabilitation Writing Committee. American Thoracic Society/ European Respiratory Society statement on pulmonary rehabilitation. Am J Respir Crit Care Med. 2006;173:1390-1413. doi: http://dx.doi.org/10.1164/rccm.200508-1211ST

48. McCarthy B, Casey D, Devane D, et al. Pulmonary rehabilitation for chronic obstructive pulmonary disease. Cochrane Database Syst Rev 2. 2015.

doi: http://dx.doi.org/10.1002/ 14651858.CD003793.pub3

49. Nishi S, Zhang W, Kuo Y, Sharma G. Pulmonary rehabilitation utilization in older adults with chronic obstructive pulmonary disease, 2003 to 2012. J Cardiopulm Rehabil Prev. 2016:1. doi: http://dx.doi.org/10.1097/hcr.0000000000000194

50. CGS Administratiors. Pulmonary rehabilitation: coverage and documentation requirements. CGS website. http://www. cgsmedicare.com/parta/pubs/news/2013/0313/cope21508. html Published March 8, 2013. Updated May 29, 2013. Accessed July 19, 2016.

51. Medpac. The hospital readmission penalty: How well is it working? MedPAC website. http://www.medpac.gov/-blog-/ medpacblog/2015/03/24/the-hospital-readmission-penaltyhow-well-is-it-working. Published March 24, 2015. Accessed July 24, 2016.

52. Barton B. National Healthcare Quality and Disparities Report chartbook on care coordination. Rockville, MD: Agency for Healthcare Research and Quality; 2016 http://www. ahrq.gov/sites/default/files/wysiwyg/research/findings/ nhqrdr/chartbooks/carecoordination/qdr2015-chartbookcarecoordination.pdf . Accessed July 27, 2016. 